\title{
A taxonomic revision of Tyrini of the Oriental region. V. Revision of the genus Lasinus Sharp, I 874 (Coleoptera, Staphylinidae, Pselaphinae)
}

\author{
Rostislav Bekchiev ${ }^{1, \dagger}$, Peter Hlaváč́2,ł, Shûhei Nomura ${ }^{3, \S}$ \\ I National Museum of Natural History, 1 Tsar Osvoboditel Blvd, 1000 Sofia, Bulgaria 2 Czech University \\ of Life Sciences, Faculty of Forestry and Wood Sciences, Department of Forest Protection and Entomology, \\ Kamýcká 1176, CZ-165 21 Praha 6-Suchdol, Czech Republic 3 Department of Zoology, National Museum of \\ Nature and Science, 4-1-1 Amakubo, Tsukuba, Ibaraki, 305-0005 Japan \\ † http://zoobank.org/8F43E7B0-4A35-42D1-B98A-7A6145F1A85B \\ † http://zoobank.org/35047200-8327-44AB-8C15-FF12C1A55805 \\ § http://zoobank.org/7D7B230B-D2CF-4AEE-AA58-AF1BEB8278C9 \\ Corresponding author: Rostislav Bekchiev (bekchiev@nmnhs.com)
}

Academic editor: Zi-Wei Yin | Received 16 June 2013 | Accepted 24 September 2013 | Published 4 October 2013

http://zoobank.org/1A460ED5-0D5A-4BDC-A4E0-B7993E5CBBB9

Citation: Bekchiev R, Hlaváč P, Nomura S (2013) A taxonomic revision of Tyrini of the Oriental region. V. Revision of the genus Lasinus Sharp, 1874 (Coleoptera, Staphylinidae, Pselaphinae). ZooKeys 340: 21-42. doi: 10.3897/ zookeys.340.5980

\begin{abstract}
The genus Lasinus Sharp, 1874 of the Pselaphodes complex of genera (Pselaphitae: Tyrini: Tyrina) is revised. The three so far known species, L. mandarinus Raffray, 1890, L. monticola Sawada, 1961 and L. spinosus Sharp, 1874 are redescribed. Eight new species, L. sinicus sp. n. from China, L. mikado sp. n., L. yamamotoi sp. n., L. inexpectatus sp. n., L. yakushimanus sp. n., L. amamianus sp. n., L. saoriae sp. n., and L. okinawanus sp. n. from Japan, are described. And all species are illustrated. Lectotypes are designated for L. mandarinus and L. spinosus. An identification key to species of the genus Lasinus is provided.
\end{abstract}

\section{Keywords}

Tyrini, taxonomy, revision, new species, Russia - Kuril Islands, China, Vietnam, Japan

Copyright Rostislav Bekchiev et al. This is an open access article distributed under the terms of the Creative Commons Attribution License 3.0 (CC-BY), which permits unrestricted use, distribution, and reproduction in any medium, provided the original author and source are credited. 


\section{Introduction}

The genus Lasinus was erected by Sharp (1874) to accommodate his new species L. spinosus from Japan. Another new species, L. mandarinus was added by Raffray (1890) from the northern Vietnam. The last known species, L. monticola, was described from Japan by Sawada (1961) who also provided illustrations of aedeagi of the presumed L. spinosus. The genus was studied by the second author (Hlavác 2003) and was included in the Pselaphodes complex of genera of the subtribe Tyrina, tribe Tyrini.

The purpose of this paper is the revision of the genus, the description of eight new species, as well as to provide a key for the identification of all species of the genus.

\section{Materials and methods}

Dry-mounted specimens were relaxed in warm water. Dissections were made using standard techniques, genitalia and small parts were mounted in Euparal or Canada balsam on acetate labels which are pinned together with the specimens. Leica S8APO microscope was used for the study. All photos were done by microscope Olympus SZ 61 with camera Olympus Colorview I. The width of head is measured through eyes.

The material used in this study is deposited in the following public and private collections:

BMNH Natural History Museum, London, United Kingdom.

MCSN Museo Civico di Storia Naturale "G. Doria”, Genova, Italy.

MNHN Muséum National d'Histoire Naturelle, Paris, France.

MHNG Muséum d'histoire naturelle de la ville de Genève, Switzerland

NMNH National Museum of Natural History, Sofia, Bulgaria

NHMW Naturhistorisches Museum, Wien, Austria

NSMT National Museum of Nature and Science, Tsukuba, Japan.

PCPH Peter Hlaváč private collection, Prague, Czech Republic

PCSK Sergei Kurbatov private collection, Moscow, Russia.

Other abbreviations and symbols used in the text: $\mathrm{p}$ (printed); h (hand-written); / (used to separate different labels). All paratypes bear the following red label: PARATYPE Genus species sp. n., Bekchiev, Hlaváč \& Nomura det., 2013. 


\section{Taxonomy}

\section{Genus Lasinus Sharp}

http://species-id.net/wiki/Lasinus

Lasinus Sharp, 1874: 106. Type species: Lasinus spinosus Sharp, 1874 (original designation, gender masculine).

Lasinus Sharp: Jeannel 1958: 121.

Lasinus Sharp: Hlaváč 2003: 286 (redescription).

Diagnosis. The genus Lasinus can be readily separated from the other genera of the Pselaphodes complex (Hlavác 2003) by a combination of the following characters: 1) head with well-defined setose frontal and vertexal foveae, 2) maxillary palpi small, with palpomeres III-IV symmetrical, neither roundly expanded nor projecting laterally, 3) antennal club three-segmented, with antennomeres VIII-IX often modified in males, 4) pronotal lateral and median foveae well-defined, 5) pronotum lacking antebasal sulcus connecting foveae, 6) pronotal longitudinal sulcus present, well- to weakly-defined, 7) tarsal segments II linear, segments III inserted at the apex of the II, 8) basal carinae on the first visible tergite (IV) present, short, 9) median setose metaventral fovea absent, 10) metaventral horny processes reduced to short, stout protuberances.

Redescription. Length $2.5-3.8 \mathrm{~mm}$. Head lacking dorsally visible postgenae, with well-defined setose frontal and vertexal foveae, maxillary palpi small, symmetric. Antennae with scapes distinctly longer than pedicels, club three-segmented, antennomeres VIII-IX often modified in males, species characteristic. Pronotum with well-defined median and lateral foveae, longitudinal sulcus sometimes weakly-defined but always present, antebasal transverse sulcus absent. Elytra with two basal foveae and two striae, lacking carinae, punctate, covered by short, golden pubescence. Metaventrite with two stout, short protuberances instead of long horn-like processes, metaventral apex sharp, with shallow excavation, surface punctate and pubescent, median metaventral fovea absent. Legs long and slender, roughly punctate and pubescent, protrochanters, mesotrochanters, profemora and mesofemora with spines of various shape and length, metatrochanters and metafemora lacking spines, tarsomeres II linear, tarsomeres III inserted at the apex of II.

Sexual dimorphism. Females of all species bear on mesotrochanters one or two more spines than males, females antennomeres VII-IX simple, without modification.

Relationship. Due to the simple second tarsal segments and the absence of the median metaventral foveae, Lasinus is most closely related to the genera Paralasinus Hlaváč \& Nomura, 2001, Pselaphodes Westwood, 1870 and Dayao Yin, Li \& Zhao, 2011. From the latter two genera Lasinus can be separated by the completely symmetric palpomeres II-IV. In Pselaphodes and Dayao, the maxillary palpi have at least some palpomeres II-IV asymmetric, roundly expanded, or slightly to distinctly projecting 
laterally. Lasinus differs from Paralasinus by the pronotum lacking an antebasal sulcus, which is present in Paralasinus.

Habitat. Members of the genus are usually collected by sifting leaf-litter in forested areas.

Distribution. China, Vietnam, Japan, Russia (Kuril Islands).

\section{Key to species of Lasinus}

1 Pronotum with prominent lateral swellings before lateral foveae (Figs 1, 4, 9). Body length 3.25-3.60 mm. Species from Vietnam or China ................... 2

- $\quad$ Pronotum evenly rounded (Figs 5, 8) or with weak swellings (Fig. 10) before lateral foveae. Body length 2.70-3.30 mm. Species from Japan..................3

2 Antennomeres X elongate, about 1.6 times longer than wide (Fig. 1). (male unknown). Vietnam. L. mandarinus Antennomeres X short, about as long as wide in both sexes (Fig. 4). China ..

L. sinicus

Antennomeres IX in male simple, only slightly obliquely trucate apically ... 4 Antennomeres IX in male modified, with well-defined sexual character ......5 Antennomeres VII 1.3 times longer than wide; antennal club as in Fig. 15...

L. inexpectatus

Antennomeres VII 1.15 times longer than wide; antenal club as in Fig. 14

L. yamamotoi

Antennomeres IX with well-developed preapical tubercule ......................6

Antennomeres IX with different type of ornamentation ........................... 7

Antennomeres VIII 1.16 times longer than wide; antennal club as in Fig. 17 ...

L. amamianus

Antennomeres VIII 0.9 times longer than wide; antennal club as in Fig. 18..

L. saoriae

Antennomeres IX with shallow concavity, lacking apical nail-shaped protuberance....

Antennomeres IX with apical nail-shaped protuberance. Antennomeres IX almost rectangular; antennal club as in Fig. 11.... L. spinosus Antennomeres IX with strong, internal obliquity at apex; antennal club as in Fig. 19

L. okinawanus Antennomeres IX with deep concavity; antennal club as in Fig. 13.... L. mikado Antennomeres IX with shallow concavity; antennal club as in Figs 12-16... 10 Genae angulate, with triangular, prominent protuberance (Fig. 6); pronotum evenly rounded before lateral fovea (Fig. 8); antennal club as in Fig. 12; aedeagus as in Fig. 21

- $\quad$ Genae convex, with weak protuberance (Fig. 7); pronotum with weak swellings before lateral fovea (Fig. 10); antenal club as in Fig. 16. Aedeagus as in Fig. 25 


\section{Lasinus mandarinus Raffray, 1890}

http://species-id.net/wiki/Lasinus_mandarinus

Fig. 1

Lasinus mandarinus Raffray, 1890: 212, Pl. III, fig. 16.

Type locality. Tonkin (Ha Noi, Vietnam).

Material examined ( 4 $q$ ) $)$. LECTOTYPE, $q$, here designated: (h) Tonkin / red label (p) TYPE / (h) L. mandarinus (p) A. Raffray det. / (p) MUSÉUM PARIS, 1917, COLL. A. RAFFRAY / red label (p) LECTOTYPE Lasinus mandarinus Raffray, Bekchiev, Hlaváč \& Nomura des., 2013. (MNHN). PARALECTOTYPES, 3 o : : same data as lectotype, bearing the following red label: (p) PARALECTOTYPE Lasinus mandarinus Raffray, Bekchiev, Hlaváč \& Nomura des., 2013. (MNHN).

Lectotype designation. Redescription of this species given below is based on four females deposited in MNHN having a status of syntypes. Raffray (1890) also mentioned four females in his original description. One female is here designated as lectotype, and three remaining females paralectotypes, in order to ensure the stability of nomenclature and provide a unique name-bearing type for Lasinus mandarinus.

Description. Body (Fig. 1) unicoloured, dark brown, maxillary palpi yellow, length 3.30-3.60 mm.

Head elongate, about 1.15 times longer than wide, slightly longer than pronotum; median sulcus well-defined along whole length of head. Genae simple, without protuberance.

Antennae very long, about $2.3-2.4 \mathrm{~mm}$; scapes about 5 times longer than pedicels, pedicels short, as long as wide; antennomeres III-VII subequal in length, slightly shorter than V; antennomeres VI-VIII about as long as pedicels; IX slender, 2.25 times longer than wide, 1.10 times as long as $\mathrm{X}$; late about 1.6 times longer than wide; terminal segments 1.2 times as long as $\mathrm{X}$ and 1.6 times longer than wide.

Pronotum as long as wide, gibbose, with prominent lateral swellings before lateral foveae; lateral and median setose foveae well-defined; median sulcus originates in median fovea and almost reaching anterior margin of pronotum.

Legs long and slender; protrochanters with small apical spine; profemora with long spine before middle; mesotrochanters at apex with two spines, outer one fairly bigger; mesofemora with minuscule spine at basal third.

First visible abdominal tergite (IV) glabrous, slightly more than two times longer than second $(\mathrm{V})$; short basal carinae well-defined, distance between carinae 0.4 of maximal tergal width.

Differential diagnosis. Lasinus mandarinus is close to L. sinicus by the pronotum with prominent lateral swellings before lateral foveae, but it differs from the latter by the proportion of antennomere $\mathrm{X}$ which is 1.6 times as long as wide.

Distribution. Vietnam (Tonkin, Ha Noi). 


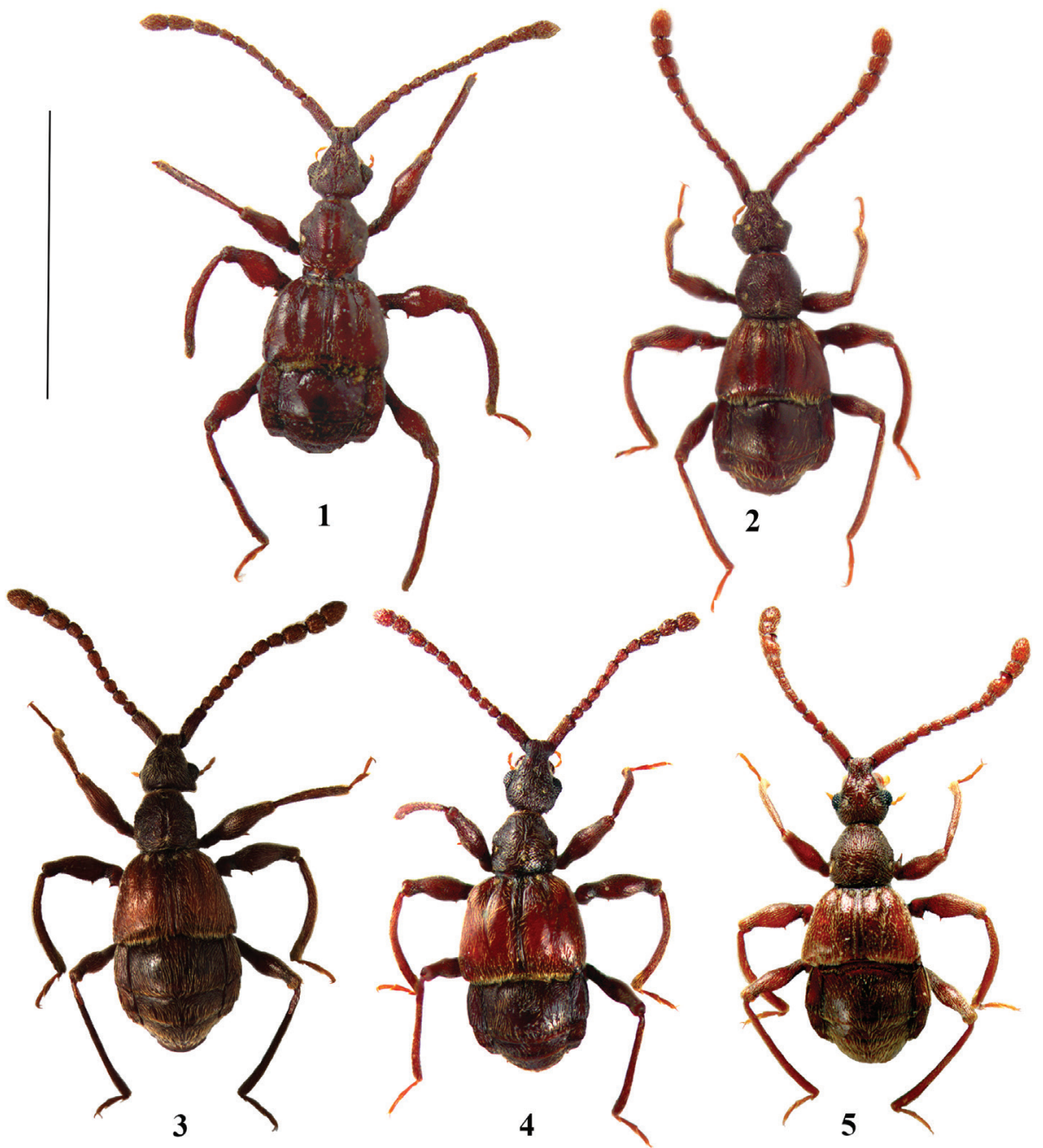

Figures I-5. Habitus of Lasinus species. I L. mandarinus 2 L. spinosus 3 L. monticola 4 L. sinicus 5 L. mikado. Scale $-3.0 \mathrm{~mm}$.

\section{Lasinus spinosus Sharp}

http://species-id.net/wiki/Lasinus_spinosus

Figs 2, 11, 20

Lasinus spinosus Sharp, 1874: 106.

Lasinus spinosus Sharp: Waterhouse 1882, 90: pt. 21, pl. 146, fig. 3.

Type locality. Nagasaki, Suwo-sama (=Suwa shrine).

Type material examined. LECTOTYPE, $\widehat{O}$, here designated: (h) Lasinus spinosus. Type D.S. Japan. Lewis. [label where the type specimen was originaly mounted] 
/ (h) Lasinus spinosus đ̋ (p) TYPE (h) D. S. / (p) Japan. G. Lewis / round label with red margin (p) TYPE / round label with blue margin (p) SYNTYPE / (p) Sharp Coll. 1905-313. / red label (p) LECTOTYPE Lasinus spinosus Sharp, Bekchiev, Hlavác \& Nomura, des., 2013 (BMNH). PARALECTOTYPE, 1 ㅇ, here designated: (h) Lasinus spinosus + (p) TYPE (h) D. S. / (p) Japan. G. Lewis / round label with blue margin (p) SYNTYPE / red label (p) PARALECTOTYPE Lasinus spinosus Sharp, Bekchiev, Hlaváč \& Nomura, des., 2013 (BMNH).

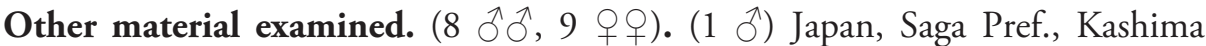
City, Mt. Kyogatake., 19.X.1986, S. Nomura leg.; (1 Ĵ) Japan, Fukuoka Pref., Hiko-san Mts., 3.V.1983, S. Nomura leg.; (1 ô) Japan, Kumamoto Pref., Ueki-cho, 10.IV.1981, S. Naomi leg.; (1 §’, 1 O) Japan, Kyushu, Nagasaki Pref., Isahaya-shi, Jôyama, Atagoyama, 18.III.1998, S. Nomura leg.; (1 đ̊) Japan, Kyushu, Oita Pref., Shonai-machi, Nishi-Ohara, 20.VI.1998, K. Ôtsuka leg.; (1 O, 1 ㅇ) Japan, Kyushu, Miyazaki Pref., Tano-cho, Aoidake, 6.IX.1993, S. Nomura leg.; (1 §, 1 †) Japan, Fukuoka, Hikosan Mts., 27.XII.1982, S. Nomura leg.; (1 §̂, 1 †) Japan, Nagasaki City, Suwa Shrine, 2.V.1985, S. Nomura leg.; (1 ㅇ) Japan, Miyazaki Pref., Kiyotake-cho, Kaeda vall., 27.IV.1993, S. Nomura leg.; (2 o + ) Japan, Miyazaki Pref., Aya-Minami, 9.V.1985, S. Nomura leg.; (2 + + ) Japan, Kyushu, Oita Pref., Kujû Mts., Makinoto pass., 14.X.1991, S. Nomura leg. (NSMT, PCPH, NMNH, PCSK).

Lectotype designation. Redescription of this species given below is based on one male and one female deposited in BMNH having a status of syntypes. Sharp (1874) mentioned three specimens in his original description. One male is here designated as lectotype, another female is paralectotype, in order to ensure the stability of nomenclature and provide a unique name-bearing type for Lasinus spinosus.

Description. Body (Fig. 2) unicoloured, reddish-brown, maxillary palpi yellow, length $2.90-3.10 \mathrm{~mm}$.

Head elongate, about 1.15 times longer than wide, slightly longer than pronotum; median sulcus visible on rostrum and on vertex reaching level of vertexal foveae. Genae with weak protuberance, covered with erected, dense golden setae.

Antennae about $2.02 \mathrm{~mm}$ long (Fig. 11); scapes long, about 3.7 times longer than pedicels; pedicels about 1.18 times shorter than antennomeres III; antennomeres IV and V as long as wide; antennomeres VI 1.22 times shorter than pedicels; antennomeres VII 1.25 times shorter than VI; antennomeres VIII about 1.27 times longer than and distinctly wider than VII; IX about 1.5 times longer than wide and about same length as terminal antennomeres, IX in male with small and shallow discoidal plate on apical half bearing small pore-like structure with one long seta, in female unmodified; antennomeres $\mathrm{X}$ quadrate, 1.5 times shorter than IX; terminal antennomeres 1.6 times longer than $\mathrm{X}$ and about 1.5 times longer than wide.

Pronotum about as wide as long, wrinkly, evenly rounded before lateral foveae; lateral and median setose foveae well-defined; median longitudinal sulcus very thin, but distinct.

Legs long and slender; protrochanters with large apical spine; profemora with long spine in middle of its length; mesotrochanters at apex with one small (male) or two 
(female) spines, in some cases one spine is slightly stronger; mesofemora with minuscule spine at basal third.

Abdomen slightly wider than elytra, first visible abdominal tergite (IV) finely punctate with dense and short golden setae, about 4 times as long as next tergite, basal carinae very short, distance between carinae 0.4 of maximal tergal width. Aedeagus (Fig. 20) $0.64 \mathrm{~mm}$ long; median lobe weakly narrowed apically, with short and large apical lobe; endophallus with two spines and one lamella; dorsal spine very big, enlarged at apex, forming large plate; ventral spine long, acute at apex; lamella small finely dentate in apical part; parameres short and slender, not overlapping apical lobe.

Differential diagnosis. Lasinus spinosus shares with $L$. monticola, $L$. mikado, $L$. inexpectatus, L. saoriae and L. yamamotoi the evenly rounded pronotal lateral margins, but differs from all of these species by the shape of the antennae and aedeagus.

Distribution. Japan (Kyushu).

\section{Lasinus monticola Sawada}

http://species-id.net/wiki/Lasinus_monticola

Figs 3, 6, 8, 12, 21

Lasinus monticola Sawada, 1961: 41; pl. 7, figs 1, 3, 4.

Type locality. Hiko (900 m), Fukuoka, Kyushu.

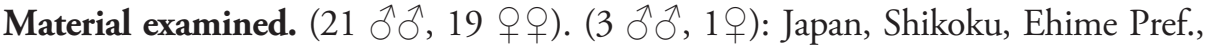
Oda-cho, Mt. Odamiyama, Buna st., 2.IX.1993, E. Yamamoto leg.; (1 Ô) Nara, Nara Park, 8.VIII.1980, I. Löbl leg.; (1 +) Japan: Honshu, Kanagawa Pref., Aikawa-chô Mt., Hasuge-san, 7.I.2006, T. Lackner leg.; (1 §) Japan, Fukushima pref, Okutadami, Alizu,

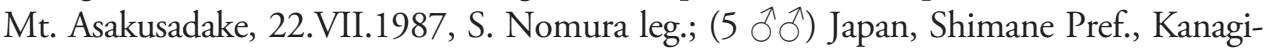

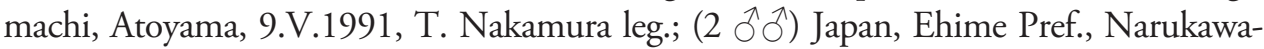
keikoku 600-700 m, 1.II.1997, M. Sakai leg.; ( 1 §) Japan, Ehime Pref, Komi, Yanadani, 2.X.1994, M. Sakai leg.; (1 ठ, 7 q + ) Japan, Kyushu, Kagoshima Pref., Kirishima, Kurinodake Spa, 8.III.1999, H. Hoshina leg.; (1 ठ) Japan, Kyushu, Miyazaki Pref., Tsuno-chô, Mt. Osuzuyama, 700 m, 8.IX.1994, S. Nomura leg.; (2 హే $\left.^{\lambda}\right)$ Japan, Kyushu, Miyazaki Pref., Takachiho-chô, Onino-iwaya, 3.XII.1994, S. Nomura leg.; (1 đ̊) Japan, Kyushu, Miyazaki Pref., Wanizukayama Mts., 6.IX.1993, S. Nomura leg.; (1 ô, 1 q) Japan, Kyushu, Miyazaki Pref., Aya-chô, 10.II.1994, S. Nomura leg.; (1 ठ̂̉) Japan, Kyushu, Kagoshima Pref., Aira-chô, 30.I.1985, T. Tanabe leg.; (1 +) Japan, Honshu, Tokyo Pref., Fussa-shi, Tamagawa Riverside, Mutsumi-bashi, 12.II.2007, S. Nomura leg.; (1 + ) Japan, Honshu, Tokyo Pref., Okutama, Nippara, Ogawadani, 4.IV.2006, S. Nomura leg.; (4 우) Japan, Kyushu, Nagasaki Pref., Unzen Mt. Kinugasayama, 16.III.2007, S. Nomura leg.; (1 O) Japan, Kyushu, Kagoshima Pref., Osumi Mt., Hoyoshidake, 19.III.1994, S.

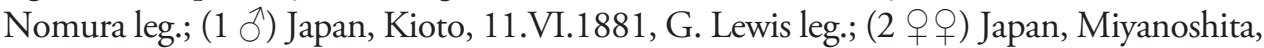
11.VI.1881, G. Lewis leg. (BMNH, NSMT, PCPH, NMNH, PCSK). 

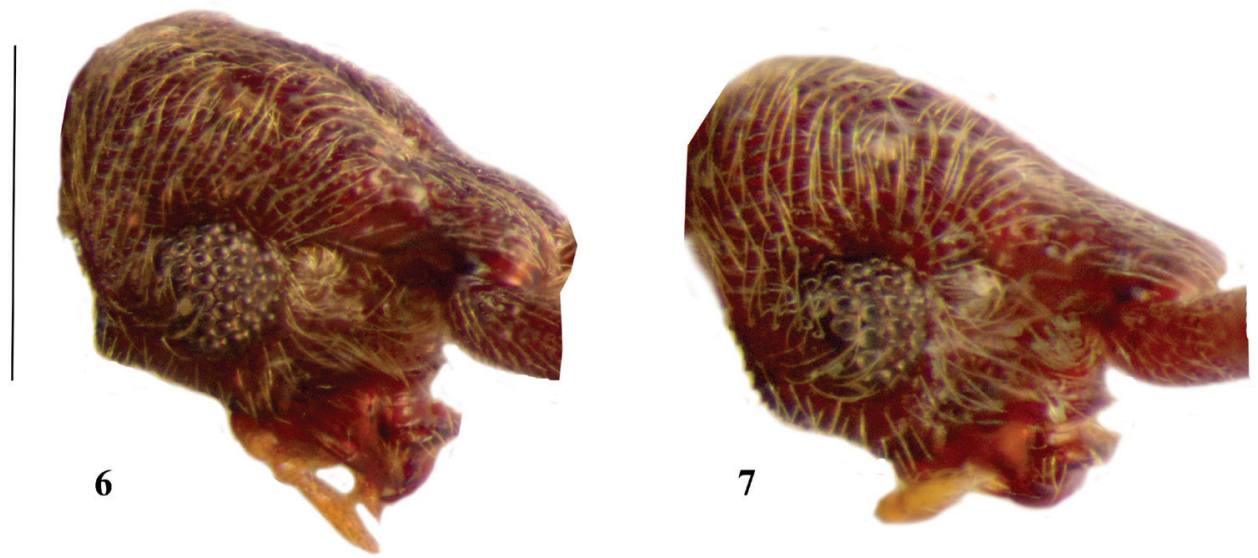

Figures 6-7. Head of L. monticola (6) and L. yakushimanus (7) lateral view. Scale $-0.4 \mathrm{~mm}$.

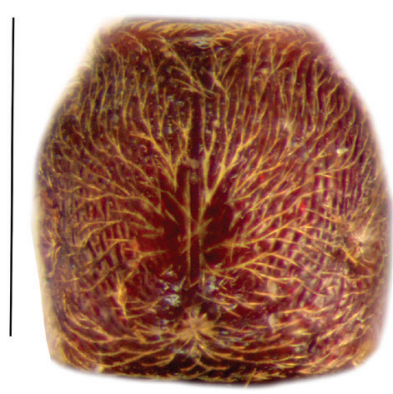

8

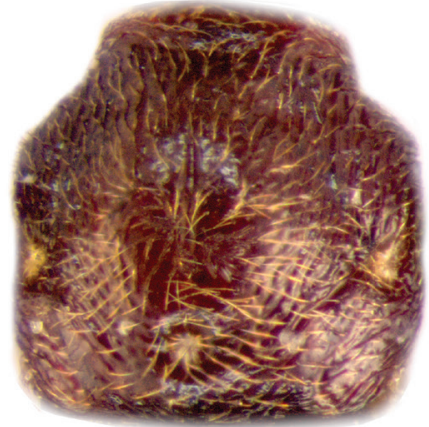

9

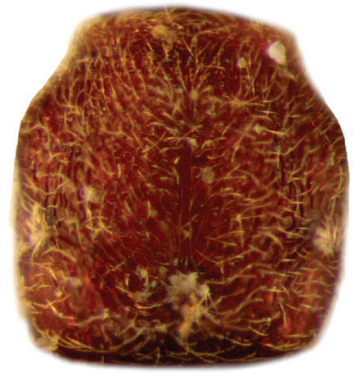

10

Figures 8-10. Pronotum of L. monticola (8) L. sinicus (9) and L. yakushimanus (10) dorsal view. Scale $-0.6 \mathrm{~mm}$.

Description. Body bicoloured (Fig. 3), darker brown with more reddish elytra, maxillary palpi yellow, length $2.80-3.30 \mathrm{~mm}$.

Head elongate, about 1.06 times longer than wide and as long as pronotum; median sulcus weakly defined along whole length of head. Genae with triangular, prominent protuberance, covered with erect, dense golden setae (Fig. 6).

Antennae about $2.23 \mathrm{~mm}$ long (Fig. 12); scapes long, about 4 times longer than pedicels; pedicels shortest, quadrate and as long as IV and V each; antennomeres III about 1.25 times longer than pedicels; antennomeres VI-VII subequal in length; VIII slightly shorter than VII; IX about 1.5 times longer than wide, with apical, nail-shaped protuberance on ventral side in male, in female unmodified; antennomeres X quadrate, 1.25 times shorter than IX; terminal antennomeres 1.5 times longer than $\mathrm{X}$ and about 1.5 times longer than wide. 

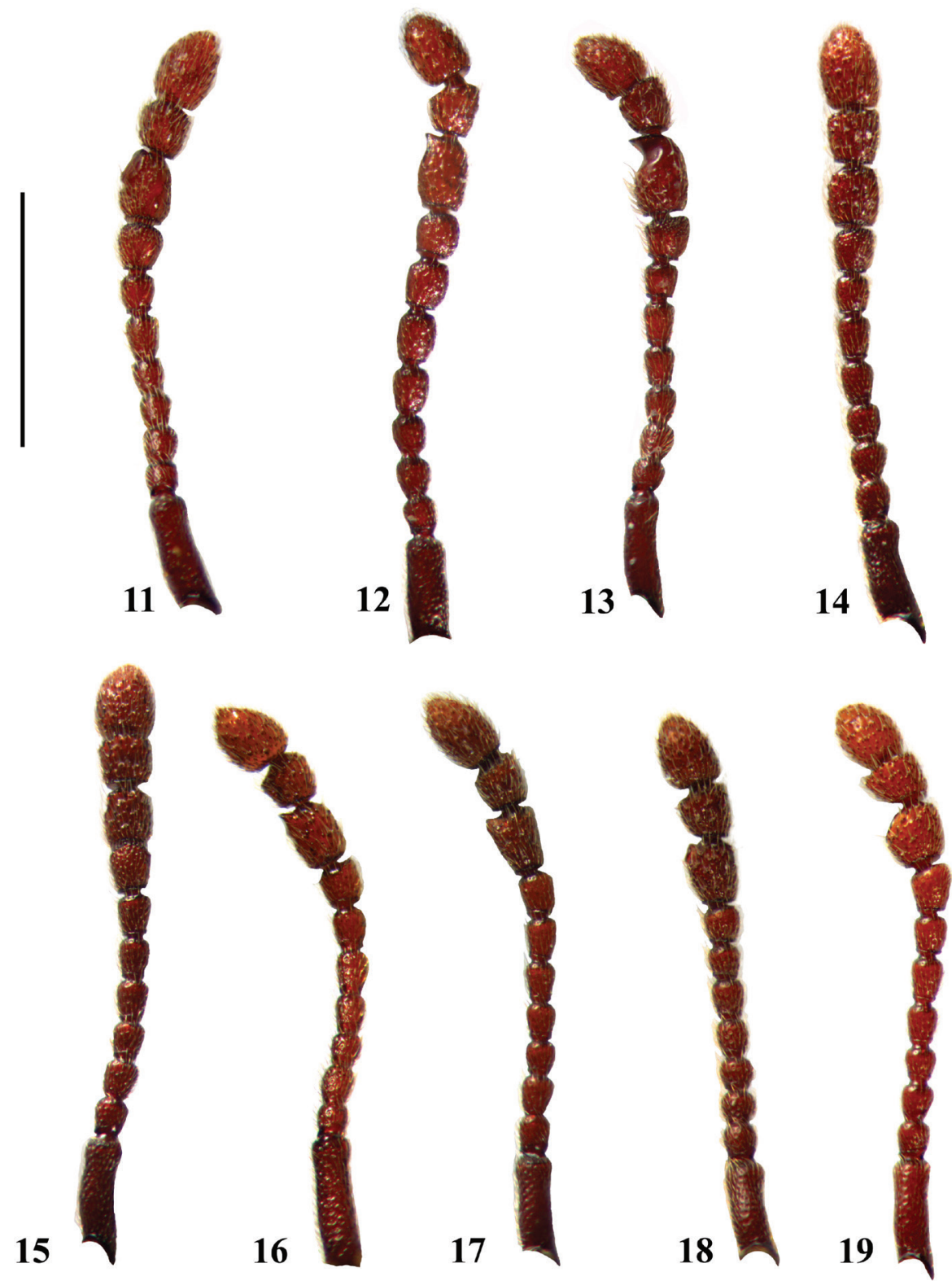

Figures I I-19. Antenae of Lasinus species (Japan). I I L. spinosus $\mathbf{2}$ L. monticola $\mathbf{1 3}$ L. mikado $\mathbf{1 4}$ L. yamamotoi 15 L. inexpectatus $1 \mathbf{6}$ L. yakushimanus 17 L. ammamnianus 18 L. saoriae 19 L. okinawanus. Scale $-1 \mathrm{~mm}$.

Pronotum slightly longer than wide, wrinkly, evenly rounded before lateral foveae (Fig. 8); lateral and median setose foveae well-defined; median sulcus weakly-defined.

Legs long and slender; protrochanters with small apical spine; profemora with long spine before middle; mesotrochanters at apex with two (males) minuscule spines 
or three (females) spines, median one minuscule; mesofemora with minuscule spine at basal third.

Abdomen slightly wider than elytra, first visible tergite (IV) about 3 times as long as second (V), finely punctate with dense, very short golden setae ; basal carinae welldefined but very short, distance between carinae 0.5 of the maximal tergal width. Aedeagus (Fig. 21) $0.66 \mathrm{~mm}$ long; median lobe weakly narrowed apically, with short and large apical lobe, curved downwards in middle; endophallus with two spines and one large lamella; dorsal spine large, enlarged in middle to form broad plate, acutely angled at apex, with one small tooth in middle; ventral spine short, acute at apex; lamella large; parameres long, overlapping apical lobe, enlarged apically.

Differential diagnosis. Lasinus monticola is close to L. mikado and L. yakushimanus by the presence of nail-shaped protuberance on the antennomeres IX, but it differs from L. yakushimanus by the shape of the genal region of the head and the pronotum, and it differs from L. mikado by the absence of a deep concavity on antennomeres IX. Lasinus monticola can be readily separated from both species also by the shape of aedeagus.

Distribution. Japan (Honshu, Shikoku, Kyushu).

\section{Lasinus sinicus sp. $\mathbf{n}$.}

http://zoobank.org/2ADC741B-FF05-41DD-BE15-56412786449F

http://species-id.net/wiki/Lasinus_sinicus

Figs 4, 9, 22

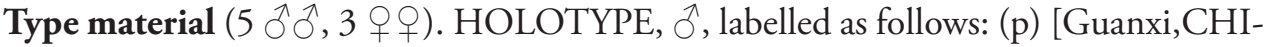
NA], "locality in Chinese characters", 25.V.1996, S. Uéno leg. / (p) ab. Liangshui 1710 m, Mt. Miao'ershan, Xing'an Xian. / red label (p) HOLOTYPE Lasinus sinicus sp. n., Bekchiev, Hlaváč \& Nomura det., 2013. (NSMT). PARATYPES: $1 \delta^{\Uparrow}$ : China, Vill, 86, Gansu: Mrijishan (h), 1000 m, Rougemont: 1 ô, 2 우: same data as holotype, but specimens collected on 26.V.1996; 1 ग, 1 ㅇ: China, Shaanxi, Nanwutaishan, 4.04.03, leg. Rougemont; 1 गे: China, W Hubei, 21.VI-13.VII, Guanmenshan-1500 m, pit fall traps, 31.45 N 110.4 E, leg. Jaroslav Turna, 2003. All paratypes bear the following red label: (p) PARATYPE Lasinus sinicus sp. n. Bekchiev, Hlaváč \& Nomura det., 2013. (NSMT, MCSN, PCPH).

Description. Body (Fig. 4) bicolored, head, pronotum and abdomen almost black, elytra reddish-brown, maxillary palpi yellow, length $3.25-3.50 \mathrm{~mm}$.

Head elongate, about 1.15 times longer than wide, slightly longer than pronotum; median sulcus absent along whole length of head. Genae simple, lacking protuberances.

Antennae long about $2.10 \mathrm{~mm}$; scapes long, about 4 times longer than pedicels; pedicels shortest, 1.25 times shorter than antennomeres III; antennomeres III, IV, VII and VIII subequal in length, slightly shorter than V and VI ; antennomeres XI 0.71 times longer than wide only slightly enlarged on the apex of antennomeres in male, in female unmodified; X 0.85 times longer than wide; XI 0.66 times longer than wide. 


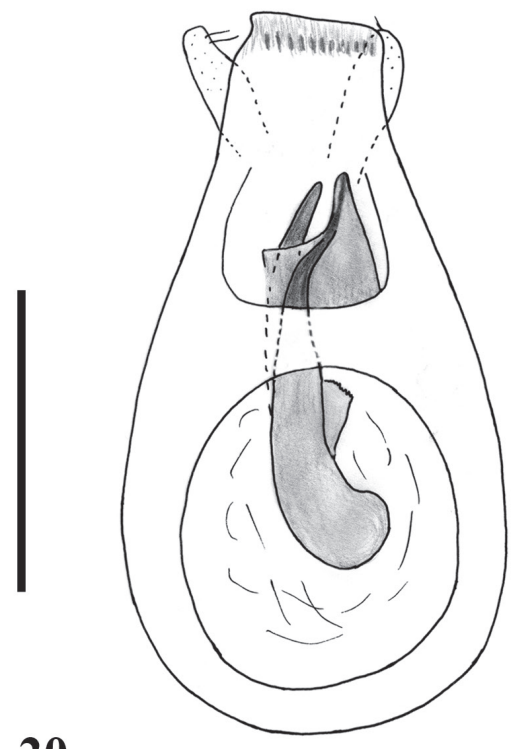

20
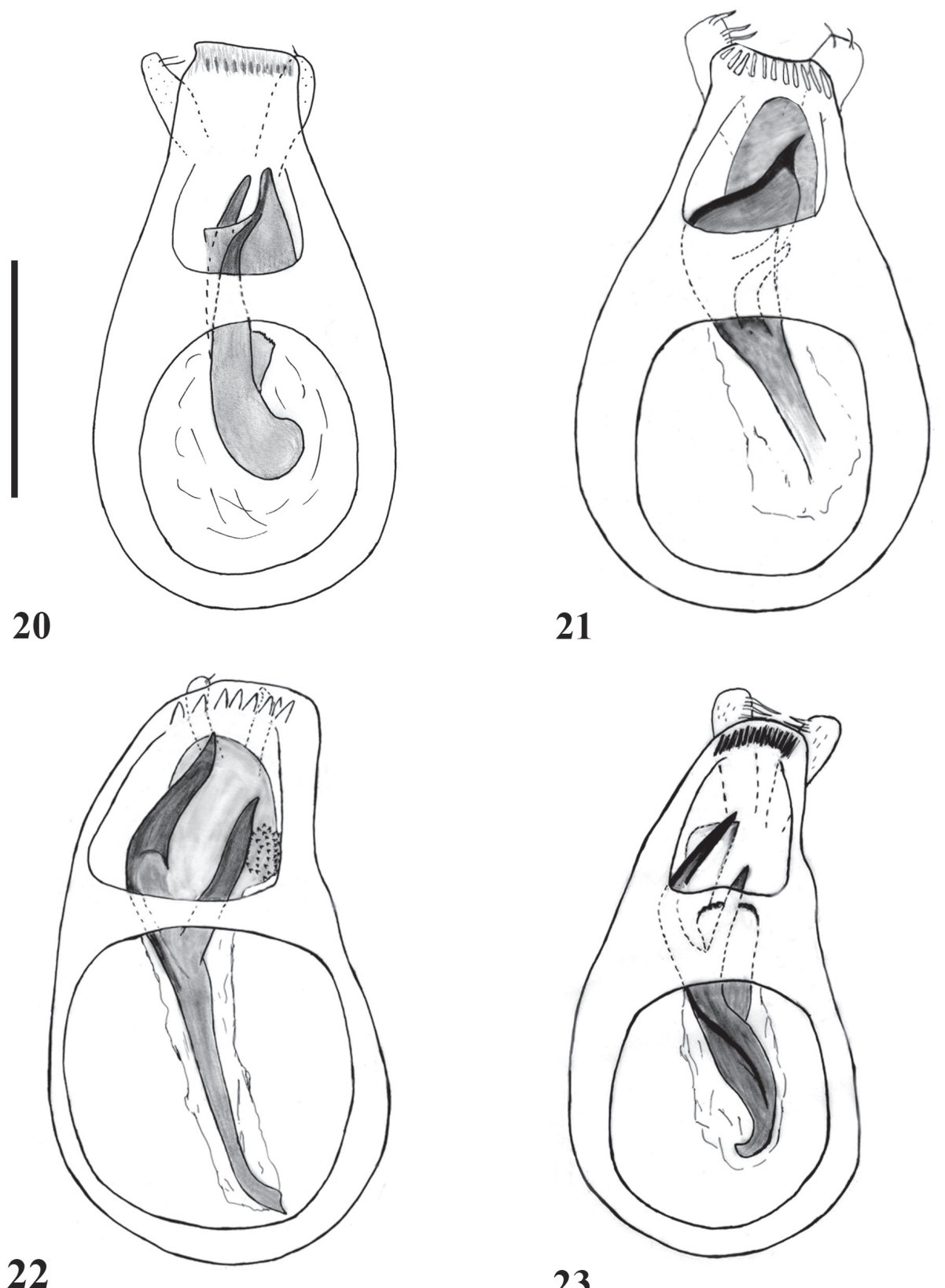

23

Figures 20-23. Aedeagi of Lasinus species (dorsal view). 20 L. spinosus $\mathbf{2 1}$ L. monticola 22 L. sinicus 23 L. mikado. Scale $-0.3 \mathrm{~mm}$.

Pronotum about as long as wide, wrinkly, gibbose, with prominent lateral swellings before lateral foveae (Fig. 9); lateral and median setose foveae well-defined; median sulcus present only on disc, not originates from median fovea, very short and fine, largely separated from anterior margin of pronotum. 
Legs long and slender; protrochanters with small apical spine; profemora with small spine in middle; mesotrochanters at apex with small median spine (male) or two (female) spines; mesofemora with small spine at basal third.

First visible abdominal tergite (IV) glabrous, very long, about 3.50 times longer than second $(\mathrm{V})$; basal carinae very short, distance between carinae about 0.5 of maximal tergal width. Aedeagus (Fig. 22) $0.66 \mathrm{~mm}$ long; median lobe weakly narrowed apically, with short and very large apical lobe; endophallus with one large, bifid spine and one lamella; lamella large, with dentation on inner left part; parameres short and slender, not overlapping apical lobe.

Differential diagnosis. Lasinus sinicus is close to L. mandarinus by the similar shape of the pronotum with prominent lateral swellings before the lateral foveae. They can be separated from it by the proportion of antennomere $\mathrm{X}$ which is almost as long as wide in L. sinicus.

Etymology. The specific name is derived from China, where the species was discovered.

Distribution. China (Guangxi, Gansu, Shaanxi, Hubei).

\section{Lasinus mikado sp. $\mathbf{n}$.}

http://zoobank.org/391BFF8A-01EF-4AE1-8AFF-22A9BDD369B3

http://species-id.net/wiki/Lasinus_mikado

Figs 5, 13, 23

Lasinus spinosus Sharp: Jeannel 1958: 121-122; figs 146, 147, 148.

Lasinus spinosus Sharp: Sawada 1961: 41; pl. 7, figs 5, 6.

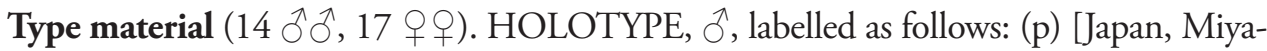
noshita, Lewis], red label (p) HOLOTYPE Lasinus mikado sp. n., Bekchiev, Hlaváč \&

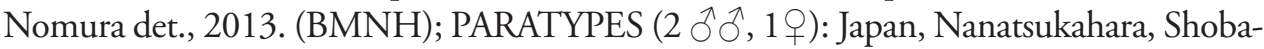
ra City, Hiroshima Pref., 10.X.1987, I. Okamoto leg.; (1 đ̂) Japan, Honshu, Chiyoda-ku, Tokyo Pref., Fukiage Gyoen, Imperial palace, 19.I.2001, S. Nomura leg.; (1 ठ̂) same data, 8.V.2001; (1 아) 18.XII.2003; (2 우) 2.II.2004; (3 우우) 12.II.2007; (1 ð̋) Japan, Honshu, Fussa-shi, Tokyo Pref., Tamagawa riverside, Mutsumi-bashi, 12.II.2007, S. Nomura leg.; $\left(\begin{array}{ll}1 & \text { }\end{array}\right)$ Japan, Honshu, Akiu-machi, Miyagi Pref., Futakuchi Valley, 27.VII.1990, S. Nomura leg.; $(3 \hat{\jmath} \hat{\jmath}, 1$ ) Japan, Honshu, Saitama Pref., Ranzan-machi, Kagamata, 5.IV.1996, K. Toyoda leg.; (1 Ỏ) Japan, Honshu, Chiba Pref., Kôzaki-jinja, Kôzaki-machi, 14.X.2001, S. Nomura leg.; (1 วิ, 2q ) Japan, Honshu, Niiharu-mura, Gunma Pref., Hôshi-onsen, 600 m, 20.X.2001, S. Nomura leg.; (2 + 우) Japan, Niigata Pref., Kuroiwa, Shibata, 22.XI.1990, H. Koike leg.; (1 §) Japan, Nara, 27-31.VII.1980, C. Besuchet

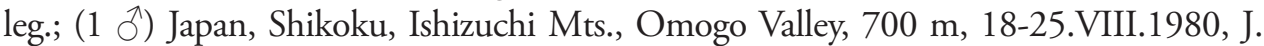

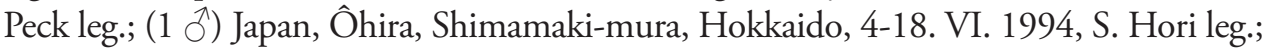

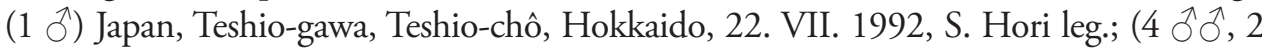
우) Russia, Kunashir Island, Tretiakovo VIII., 20.VII.1990, S. Kurbatov leg.; (1 ㅇ) same

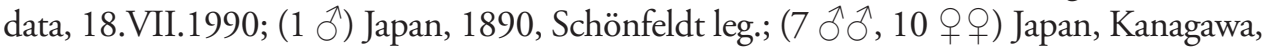
Sauter leg., (BMNH, NSMT, NHMW, NMNH, MHNG, PCPH, PCSK). 
Description. Body (Fig. 5) unicoloured, reddish-brown, maxillary palpi light brown, length $2.87-3.1 \mathrm{~mm}$.

Head elongate, about 1.10 times longer than wide, slightly longer than pronotum; median sulcus visible on rostrum, on vertex reaching level of vertexal foveae. Genae with weak protuberance, covered with erected, dense golden setae.

Antennae about $2.15 \mathrm{~mm}$ long (Fig. 13); scapes long, about 3.4 times longer than pedicels; pedicels about 1.18 times shorter than antennomeres III, antennomeres $\mathrm{V}$ and VI as long as pedicels; VII 1.25 times shorter than VI; antennomeres VIII about 1.27 times longer and distinctly wider than VII; antennomeres IX about 1.5 times longer than wide, about the same length as terminal antennomeres, in male with deep ventral concavity on apical half terminating with nail-shaped protuberance, in female unmodified; antennomere X quadrate, 1.5 times shorter than IX; terminal antennomeres 1.6 times as long as $\mathrm{X}$ and about 1.5 times longer than wide.

Pronotum about as wide as long, wrinkly, evenly rounded before lateral foveae; lateral and median setose foveae well-defined; median sulcus thin.

Legs long and slender; protrochanters with large apical spine; profemora with long spine in middle of its length; mesotrochanters at apex with two minuscule (male) or two strong (female) and one minuscule spine; mesofemora with minuscule spine at basal third.

Abdomen slightly wider than elytra; first visible abdominal tergite (IV) finely punctate, with dense and long golden setae, about 4 times longer than second visible tergite (V); basal carinae very short, distance between carinae 0.53 of maximal tergal width. Aedeagus (Fig. 23) $0.61 \mathrm{~mm}$ long; median lobe weakly narrowed apically, with long and relatively narrow apical lobe; endophallus with one bifid spine and two small lamellas; lamellas finely dentate on the apical part; parameres long, overlapping apical lobe, enlarged at apex.

Differential diagnosis. Lasinus mikado is close to L. monticola and L. yakushimanus by the presence of a nail-shaped protuberance on antennomeres IX, it differs from both by the presence of a deep concavity on antennomeres IX and by the shape of aedeagus.

Etymology. The name is derived from the Japanese word - „mikado“, meaning the Emperor of Japan.

Distribution. Japan (Hokkaido, Honshu, Shikoku), Russia (Kuril Islands).

Remarks. The original type series of Lasinus spinosus in the Sharp collection is in fact a mix of L. spinosus and L. mikado sp. n.

\section{Lasinus yamamotoi sp. $\mathbf{n}$.}

http://zoobank.org/79AC04BB-D1ED-4108-9984-DE09D9FC6B2D

http://species-id.net/wiki/Lasinus_yamamotoi

Figs 14, 24

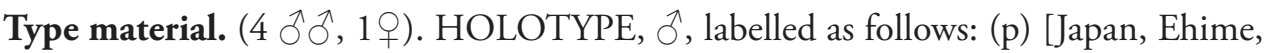
Nomura Dam, Nomura-cho, 27.V.1994, M. Sakai leg.] red label (p) HOLOTYPE Lasinus yamamotoi sp. n., Bekchiev, Hlaváč \& Nomura det., 2013. (NSMT). PARA-

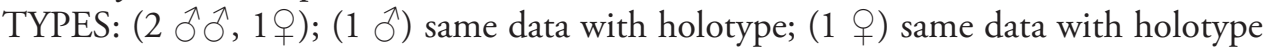




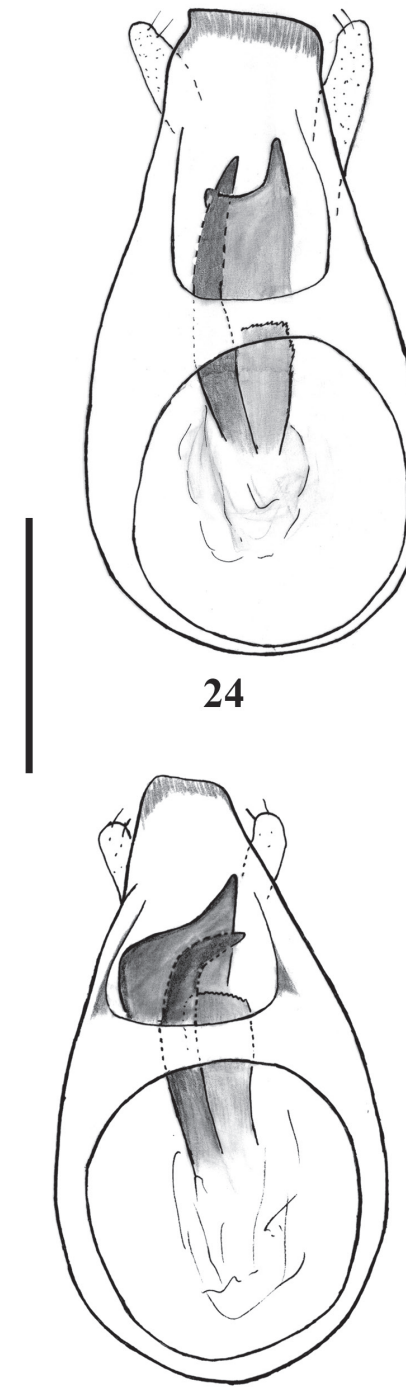

27
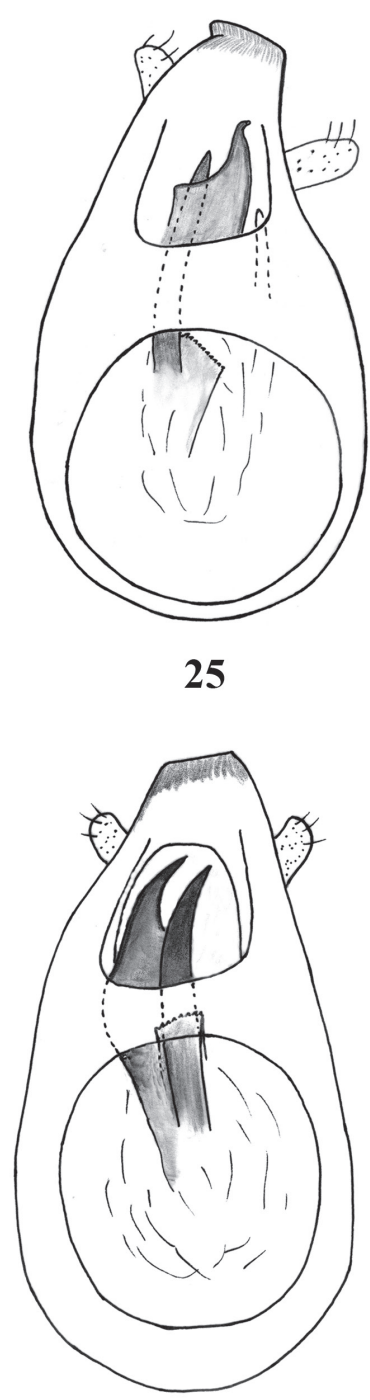

28
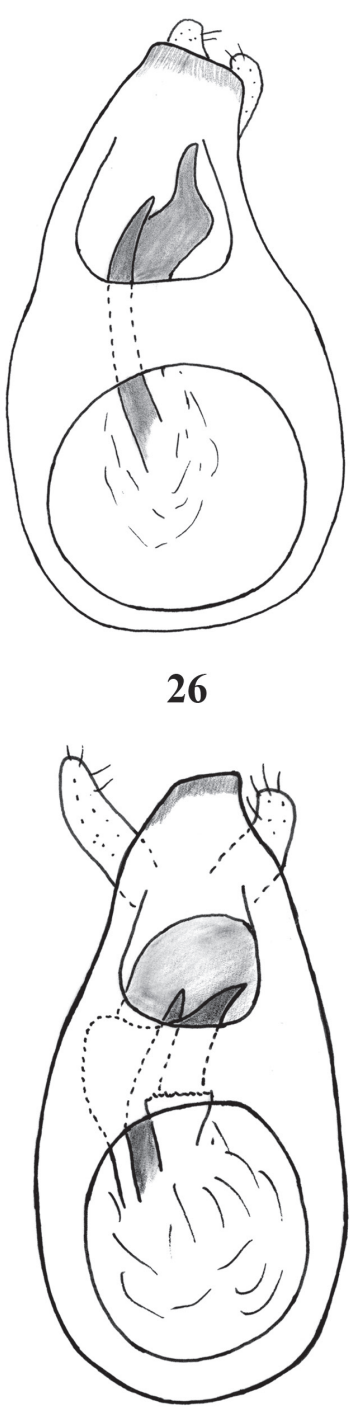

29

Figures 24-29. Aedeagi of Lasinus species (dorsal view). 24 L. yamamotoi $\mathbf{2 5}$ L. inexpectatus 26 L. yakushimanus $\mathbf{2 7}$ L. amamianus $\mathbf{2 8}$ L. saoriae $\mathbf{2 9}$ L. okinawanus. Scale $-0.3 \mathrm{~mm}$.

but in 23.VII.1994; (1 $\left.\begin{array}{l}\text { } \\ )\end{array}\right)$ Japan, Shikoku, Ehime Pref., Uchiko-chô, Shiromawari, 9.VII.1995, E. Yamamoto leg. (NSMT, PCPH, NMNH).

Description. Body unicoloured, head, pronotum and abdomen reddish-brown, elytra slightly lighter, maxillary palpi yellow, length $2.85-2.95 \mathrm{~mm}$.

Head elongate, 1.08 times longer than wide and as long as pronotum; median sulcus visible on rostrum, relatively shallow at level of vertexal foveae. Genae with weak protuberance, covered with erected, dense golden setae. 
Antennae (Fig. 14) about $2.02 \mathrm{~mm}$ long; scapes long, about 2.85 times longer than pedicels; pedicels short, 1.42 times shorter than each of antennomeres III-IV; antennomeres V and VI of same length; antennomeres VII 1.22 times longer than wide; VIII longer than wide; XI longer than wide, simple, only slightly oblique on ventral side in male, in female unmodified ; X slightly longer than wide; XI longer than wide.

Pronotum slightly longer than wide, surface evenly wrinkly, evenly rounded before lateral foveae; lateral foveae well-defined; median setose fovea small; median sulcus very thin.

Legs long and slender; protrochanters with long apical spine; profemora with short, strong spine in middle; mesotrochanters with one small (male) or two (female) spines; mesofemora with small spine at basal third.

First visible abdominal tergite (IV) very long, about four times longer than second visible tergite $(\mathrm{V})$, with fine punctation in anterior part, disc glabrous, surrounded with short golden pubescence on sides; carinae short, distance between carinae 0.4 of maximal tergal width. Aedeagus (Fig. 24) $0.57 \mathrm{~mm}$ long; median lobe weakly narrowed apically, with large and relatively short apical lobe; endophallus with two spines and small lamella; ventral spine very big, forming large plate; dorsal spine big, curved, acute at apex; lamella small, finely dentate in apical part; parameres short and slender, reaching apical lobe, enlarged at apex.

Differential diagnosis. Lasinus yamamotoi resembles $L$. inexpectatus due to the unmodified antennal clubs in both sexes, but it can be distinguished from the latter by the proportion of the antennomeres VII and the shape of the aedeagus.

Etymology. Patronimic, dedicated to Mr. Eiji Yamamoto (Japan).

Distribution. Japan (Shikoku).

\section{Lasinus inexpectatus sp. $\mathrm{n}$.}

http://zoobank.org/DD3C5D54-9348-42C5-942B-E6BAC99ACA95

http://species-id.net/wiki/Lasinus_inexpectatus

Figs 15, 25

Type material $(3 \widehat{\partial}, 19)$. HOLOTYPE, $\widehat{\partial}$, labelled as follows: (p) Japan, Kyushu, Miyazaki Pref., Aya-chô, Ôtsuribashi, 25.IV.1993, leg. S. Nomura. red label (p) HOLOTYPE, Lasinus inexpectatus sp. n., Bekchiev, Hlaváč \& Nomura det.

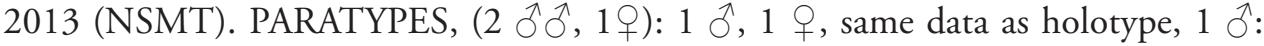
(p) Japan, Kyushu, Miyazaki Pref., Nangoh-choh, Ohshima (3), leg. Atsushi Nagai (NSMT, NMNH, PCPH).

Description. Body unicoloured, reddish-brown, elytra slightly lighter, maxillary palpi light brown, length $2.80-3.20 \mathrm{~mm}$.

Head about 1.05 longer than wide, and as long as pronotum; median sulcus very weakly-defined, slightly visible only on rostrum, absent on vertex. Genae with weak protuberance, covered with erected, dense golden setae. 
Antennae 2.20-2.24 mm long (Fig. 15); scapes long, about 3.25 times longer than pedicels; pedicels slightly shorter than antennomeres III-VII combined, which are subequal; VIII slightly longer and about 1.30 times wider than VII; antennomeres IX rectangular, simple, in male slightly shorter $(0.18 \mathrm{~mm})$ than in the female $(0.24 \mathrm{~mm})$; $\mathrm{X}$ about as wide as long; terminal antennomeres 1.60 times longer than $\mathrm{X}$.

Pronotum 1.05 times longer than wide, wrinkly, evenly rounded before lateral foveae; lateral and median setose foveae well-defined; median sulcus thin, present only on disc.

Legs long and slender; protrochanters with large apical spine; profemora with long spine in middle of its length; mesotrochanters at apex with one minuscule (male) or two strong (female) spines; mesofemora with minuscule spine at basal third.

Abdomen slightly wider than elytra; first visible abdominal tergite (IV) finely punctate with dense and long golden setae on sides, disc glabrous, about 3 times longer than second visible tergite $(\mathrm{V})$; basal carinae very short, almost invisible in males. Aedeagus (Fig. 25) $0.63 \mathrm{~mm}$ long; median lobe weakly narrowed apically, with long and narrow apical lobe; endophallus with three spines and small lamella; ventral spine large, forming large plate, acute and curved at apex; dorsal spine large, curved, acute at apex; lateral spine very slender and small, acute at the apex; lamella small, finely dentate on apical part; parameres short, unequal in length, not overlapping apical lobe, enlarged at apex.

Differential diagnosis. Lasinus inexpectatus is close to L. sinicus due to the simple antennomeres IX lacking any sexual character. The two species can be separated by the absence of swellings before lateral foveae on the pronotum in L. inexpectatus. From all other Japanese species, $L$. inexpectatus also differs by the shapes of the aedeagus and the antennae.

Etymology. The name is realated with the „unexpected” discovery of this species.

Distribution. Japan (Kyushu).

\section{Lasinus yakushimanus sp. $\mathrm{n}$.}

http://zoobank.org/2845C2F2-7942-499E-8D3E-7D5948F31728

http://species-id.net/wiki/Lasinus_yakushimanus

Figs $7,10,16,26$

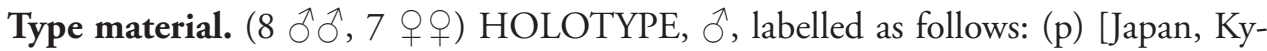
ushu, Kagoshima Pref., Yakushima, Hananoegô, 17.III.2001, H. Hoshina leg.] red label (p) HOLOTYPE Lasinus yakushimanus sp. n., Bekchiev, Hlaváč \& Nomura det.,

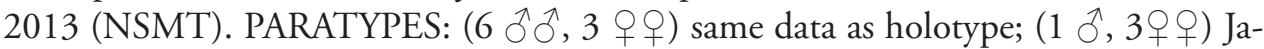
pan, Kagoshima Pref., Yakushima, Mt. Nonkidake, 1350 m, 4.IX.2006, S. Nomura leg.; (1ㅇ) Japan, Kagoshima Pref., Yakushima, Mt. Aikodake, 200 m, 5.IX.2006, S. Nomura leg. (NSMT, PCPH, NMNH, PCSK).

Description. Body unicoloured, reddish-brown, maxillary palpi yellow dark, length $2.84-2.96 \mathrm{~mm}$. 
Head elongate, about 1.07-1.11 times longer than wide and about as long as pronotum; median sulcus visible on rostrum and on vertex reaching level of vertexal foveae. Genae with weak protuberance, covered with erected, dense golden setae (Fig. 7).

Antennae about $1.94 \mathrm{~mm}$ long (Fig. 16); scapes long, about 3.0 times longer than pedicels; pedicels as long as antennomeres III; antennomeres IV and V slightly longer than wide; antennomeres VI 1.62 times longer than wide; antennomeres VII as long as wide; antennomeres VIII as long as and slightly wider than VII; IX about 1.20 times longer than wide, in male with shallow ventral excavation on apical half terminating with small nail-shaped protuberance, in female unmodified; antennomeres X 1.21 longer than wide; terminal antennomeres about 1.27 times longer than wide.

Pronotum about as wide as long, wrinkly, with weak lateral swellings before lateral foveae (Fig. 10); lateral and median setose foveae well-defined; median sulcus thin.

Legs long and slender; protrochanters with large apical spine; profemora with longer spine in middle of its length; mesotrochanters at apex with two minuscule (male) or two strong and one minuscule (female) spines; mesofemora with minuscule spine at basal third.

Abdomen slightly wider than elytra; first visible abdominal tergite (IV) finely punctate, with dense, very short golden setae; carinae short, distance between carinae 0.49 of maximal tergal width. Aedeagus (Fig. 26) $0.56 \mathrm{~mm}$ long; median lobe weakly narrowed apically, with short and large apical lobe; endophallus with two spines; ventral spine large, forming narrow curved plate; dorsal spine slender, evenly curved, acute at apex; parameres long, overlapping apical lobe, enlarged at apex.

Differential diagnosis. Lasinus yakushimanus is close to L. okinawanus by sharing the presence of weak lateral swelling on the pronotum, and to L. monticola by the presence of a nail-shaped protuberance on antennomeres IX, it differs from both by the shapes of the antennae and the aedeagus.

Etymology. The name is associated with the name of the locality, Yakushima, where the speciments was found.

Distribution. Japan (Yaku-shima Island).

\section{Lasinus amamianus sp. $\mathbf{n}$.}

http://zoobank.org/60DB4FAF-381E-45EC-9C69-6C3893DDE8BA

http://species-id.net/wiki/Lasinus_amamianus

Figs 17, 27

Material examined. (11 $\widehat{\jmath}, 9$ 우). HOLOTYPE, $\widehat{\jmath}$, labelled as follows: (p) [Japan, Ryukyus, Kagoshima Pref., Amami-ôshima Is., Mt. Yuidake, 10.VIII.1984, S. Nomura leg.,], red label (p) HOLOTYPE Lasinus amamianus sp. n., Bekchiev, Hlaváč $\&$ Nomura det., 2013. (NSMT). PARATYPES: (4 $\widehat{\jmath} \hat{0}, 4$ 우) same data as holotype; (1 $\widehat{\jmath}, 1$ 1 ) Japan, Ryukyus, Kagoshima Pref., Amami-ôshima Is., Mt. Yuidake, 15.V.1983, S. Nomura leg.; (2 $\widehat{\partial} \widehat{\partial}, 1$ ) Japan, Ryukyus, Kagoshima Pref., Amamiôshima Is., Mt. Yuidake, 8.V.1987, S. Nomura leg.; (1 đ̂) Japan, Kagoshima Pref., 
Tokunoshima Is., Mt. Inutabudake, 3.V.1988, S. Nomura leg.; (3 えぇ, 3 q⿻+口) Japan, Kagoshima Pref., Tokunoshima Is., Yonama, 4.V.1988, S. Nomura leg. (NSMT, PCPH, NMNH, PCSK).

Description. Body unicoloured, reddish-brown, elytra slightly brighter, maxillary palpi yellow dark, length $2.80-3.00 \mathrm{~mm}$.

Head elongate, about 1.10 times longer than wide, as long as pronotum; median sulcus shallow, reaching level of vertexal foveae. Genae with weak protuberance, covered with erected, dense golden setae.

Antennae about $1.96 \mathrm{~mm}$ long (Fig. 17); scapes about 3.40 times longer than pedicels; pedicels 1.40 times shorter than antennomeres III; III slightly longer than wide; IV as long as III; antennomeres V slightly longer than wide; VI about 1.20 times longer than wide; antennomeres VII 1.2 times longer than wide; VIII 1.16 times longer than wide; IX about 1.10 times longer than wide, in male with well-developed tubercles in apical ventral part, in female unmodified; antennomeres $\mathrm{X}$ as wide as long; terminal antennomeres about 1.47 times longer than wide.

Pronotum about as wide as long, wrinkly, with weak lateral swellings before lateral foveae; lateral and median setose foveae well-defined; median sulcus thin and deep.

Legs long and slender; protrochanters with large apical spine; profemora with long spine in middle; mesotrochanters at apex with one (male) or two (female) spines; mesofemora with minuscule spine at basal third.

Abdomen slightly wider than elytra, first visible abdominal tergite (IV) finely punctate with dense and long, golden setae; carinae short, distance between them 0.47 of maximal tergal width. Aedeagus ( Fig. 27) $0.59 \mathrm{~mm}$ long; median lobe weakly narrowed apically, with long and narrow apical lobe; endophallus with two spines and one small lamella; ventral spine large, enlarged, forming large plate, acute at left apex; dorsal spine very big, acute at apex; lamella large, finely dentate on apical part; parameres short and slender, reaching apical lobe.

Differential diagnosis. Lasinus amamianus and L. saoriae differ from all other species of the genus by the shape of antennae, especially by the presence of tubercles on antennomeres IX. Lasinus amamianus can be readily separated from $L$. saoriae by the proportion of antennomeres VII and VIII and by the shape of aedeagus.

Etymology. The species name is associated with the name of the locality, Amami-ôshima Island, where most of the specimens were found.

Distribution. Japan (Amami-ôshima, Tokunoshima Islands).

\section{Lasinus saoriae sp. $\mathbf{n}$.}

http://zoobank.org/D5F88EC3-FC0E-4ACE-8EEF-805AD708DFB8

http://species-id.net/wiki/Lasinus_saoriae

Figs 18, 28

Type material ( $6 \widehat{\widehat{\partial},} 6$ 우). HOLOTYPE, $\widehat{\partial}$, labelled as follows: (p) [Japan, Ryukyus, Okinawa Is., Kunigami-son, Mt. Yonahadake , 22.III.2005, S. Nomura leg.], 
red label (p) HOLOTYPE Lasinus saoriae sp. n., Bekchiev, Hlaváč \& Nomura det., 2013. (NSMT). PARATYPES: (2 $\hat{\jmath}, 5$ 우) same data as holotype; $(2 \hat{\jmath} \hat{\jmath}, 1$ ㅇ) Japan, Okinawa, Yona-Kunigami, 15.III.1985, leg. S. Nomura; (1 đ̊) Japan, Okinawa, Kunigami, 16.III.1985, leg. S. Nomura (NSMT, PCPH, NMNH).

Description. Body unicoloured, reddish-brown, maxillary palpi yellow dark, length $2.70-3.10 \mathrm{~mm}$.

Head elongate, about 1.08 longer than wide, slightly shorter than pronotum; median sulcus shallow, reaching level of vertexal foveae. Genae with weak protuberance, covered with erected, dense golden setae.

Antennae about $1.8 \mathrm{~mm}$ long (Fig. 18); scapes long, about twice longer than pedicels; pedicels 1.22 times longer than antennomeres III; antennomeres IV as long as wide; antennomeres $\mathrm{V}$ slightly longer than wide; antennomeres VI about 1.33 times longer than wide; antennomeres VII and VIII slightly longer than wide; VII 0.88 times longer than wide; VIII 0.9 times longer than wide; IX about 1.26 times longer than wide, in male with short tubercles in apical ventral part, in female unmodified; antennomeres $\mathrm{X}$ about 1.33 longer than wide; terminal antennomeres about as long as wide.

Pronotum slightly longer than wide, wrinkly, evenly rounded before lateral foveae; lateral and median setose foveae well-defined; median sulcus thin and deep.

Legs long and slender; protrochanters with large apical spine; profemora with long spine in middle of its length; mesotrochanters at apex with one (male) or three (female) spines; mesofemora with minuscule spine at basal third.

Abdomen slightly wider than elytra; first visible abdominal tergite (IV) finely punctate, with sparse golden setae; carinae very small, distance between them 0.48 of maximal tergal width. Aedeagus (Fig. 28) $0.61 \mathrm{~mm}$ long; median lobe weakly narrowed apically; endophallus with two spines and two lamellas; ventral spine large, enlarged in middle, acute at apex; dorsal spine slender, acute at apex; dorsal lamella small, finely dentate on apical part; ventral lamella large; parameres very short and slender, not reaching apical lobe.

Differential diagnosis. Lasinus saoriae strongly resembles $L$. amamianus from which it differs essentially by the shapes of the antennae and the aedeagus.

Etymology. The specific epithet is dedicated to Saori Takeuchi (Japan), a family friend of the first author.

Distribution. Japan (Okinawajima Island).

\section{Lasinus okinawanus sp. $\mathrm{n}$.}

http://zoobank.org/56DFA417-857B-4595-8FEB-7D875CD9C8EC http://species-id.net/wiki/Lasinus_okinawanus

Fig. 19, 29

Type material. ( $4 \hat{\jmath}, 4$ q 9 ). HOLOTYPE, $\widehat{\jmath}$, labelled as follows: (p) [Japan, Ryukyus, Okinawa Is., Okinawajima, Mt. Oppadake, Nakijin-son, 26.VI.1998, S. Nomura leg.], red label (p) HOLOTYPE Lasinus okinawanus sp. n., Bekchiev, Hlaváč \&

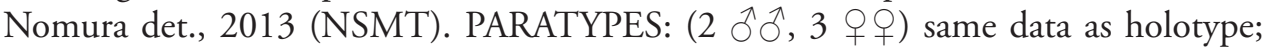


(1 Ô, 1 P) Japan, Ryukyus, Okinawa Pref., Nago-shi, Mt. Nagodake., 2.IX.2006, S. Nomura leg. (NSMT, PCPH, NMNH).

Description. Body unicoloured, light reddish-brown, maxillary palpi yellow, length 3.0-3.2 mm.

Head elongate, about 1.03 longer than wide, and as long as pronotum; median sulcus visible on rostrum, on vertex reaching level of vertexal foveae. Genae with weak protuberance, covered with erected, dense golden setae.

Antennae long about $1.94 \mathrm{~mm}$ (Fig. 19); scapes 1.16 times longer than wide, 1.40 times as long as pedicels; pedicels as long as wide and as long as antennomeres III; antennomeres IV 1.25 times shorter than III; antennomeres V 1.20 times longer than wide; antennomeres VI 1.60 times longer than wide; antennomeres VII as long as wide; antennomeres VIII about 1.40 times longer and distinctly wider than VII; antennomeres IX as long as wide and about same length as terminal antennomeres, in male with large, shallow, in apical half highly inclined discoidal plate, in female unmodified; antennomeres $\mathrm{X}$ quadrate; terminal antennomeres 1.60 times as long as $\mathrm{X}$ and about 1.37 times longer than wide.

Pronotum about as wide as long, wrinkly, with weak lateral swellings before lateral foveae; lateral and median setose foveae well-defined; median longitudinal sulcus present.

Legs long and slender; protrochanters with large apical spine; profemora with longer spine in middle of its length; mesotrochanters at apex with one (male) or three (female) spines; mesofemora with minuscule spine at basal third.

Abdomen slightly wider than elytra, first visible abdominal tergite (IV) finely punctate with sparse, short golden setae; carinae short, distance between them 0.39 of maximal tergal width. Aedeagus (Fig. 29) $0.60 \mathrm{~mm}$ long; median lobe weakly narrowed apically, with long and narrow apical lobe; endophallus with two spines and two lamellas; ventral spine very large, short, curved downwards in middle, acute rightward at apex; dorsal spine very strong, acute at apex; dorsal lamella small finely dentate on apical part; ventral lamella large; parameres long and slender, different in length, left one overlapping apical lobe, right one shorter,.

Differential diagnosis. Lasinus okinawanus is most closely related to L. spinosus by the antennomeres IX with a shallow cavity, and the lack of an apical nail-shaped protuberance. It differs from latter by antennomeres IX having highly inclined shallow discoidal plate in apical half, and by the shape of the aedeagus.

Etymology. The specific name is associated with the name of the type locality, Okinawa Island, where the type specimens were found.

Distribution. Japan (Okinawajima Island).

\section{Acknowledgement}

We thank our colleagues and reviewers Giulio Cuccodoro (Switzerland), and Zi-Wei Yin (China) for the critical reading of the manuscript, useful comments and improvement of the paper. Open access to this paper was supported by the Encyclopedia of Life (EOL) Open Access Support Project (EOASP). 


\section{References}

Hlaváč P (2003) A taxonomic revision of Tyrini of the Oriental Region II. Systematic study on the genus Pselaphodes (Coleoptera: Staphylinidae: Pselaphinae) and its allied genera. Annales de la Société entomologique de France 38: 283-297.

Hlaváč P, Nomura S (2001) A taxonomic revision of Tyrini of the Oriental Region. I. Paralasinus (Coleoptera, Staphylinidae, Pselaphinae), a new genus of Tyrina from Indochina. Elytra 29: $163-174$.

Jeannel R (1958) Revision des Pselaphides du Japon. Memoires du Museum National d'Histoire Naturelle (A: Zoologie) 18: 1-138.

Raffray A (1890) Etude sur les Psélaphides. VI. Diagnoses des espèces nouvelles sur lesquelles sont fondés des genres nouveaux. Revue d'Entomologie 9: 193-219.

Sawada K (1961) Neue Pselaphinen von Japan (3. Beitrag). Entomological review of Japan 12: $41-44$.

Sharp D (1874) The Pselaphidae and Scydmaenidae of Japan. Transactions of the Entomological Society of London 1874: 105-130.

Waterhouse CO (1882-1890) Aids to identification of insects. Janson EW, London, 189 pp.

Westwood JO (1870) Descriptions of twelve new exotic species of the Coleopterous family Pselaphidae. Transactions of the Entomological Society of London 1870: 125-132.

Yin ZW, Li LZ, Zhao MJ (2011) Dayao gen. n. of the subtribe Tyrina (Coleoptera, Staphylinidae, Pselaphinae) from South China. ZooKeys 141: 45-52. doi: 10.3897/zookeys.141.1948 